\title{
SUMBER HISTORIS PANCASILA SEBAGAI KAJIAN SUMBER SOSIOLOGIS PANCASILA
}

\author{
REGINA AUDRI \\ reginaaudry65@gmail.com \\ 20220079 \\ STIE AKBP KBP PADANG
}

\section{A. PENDAHULUAN}

Tantangan Pendidikan Pancasila Dalam menentukan bentuk dan format agar mata kuliah Pendidikan Pancasila dapat diselenggarakan di berbagai program studi dengan menarik dan efektif terdapat berbagai tantangan. Tantangan ini dapat berasal dari internal perguruan tinggi, misalnya faktor ketersediaan sumber daya, dan spesialisasi program studi yang makin tajam (yang menyebabkan kekurangtertarikan sebagian mahasiswa terhadap Pendidikan Pancasila). Tantangan yang bersifat eksternal, antara lain adalah krisis keteladan dari para elite politik dan maraknya gaya hidup hedonistik di dalam masyarakat. Untuk mengetahui lebih dalam mengenai dinamika dan tantangan Pendidikan Pancasila pada era globalisasi, perlu menganalisis penggalan-penggalan pidato kebangsaan yang sudah pernah dilakukan oleh para tokoh bangasa (founding father).

Dalam Pasal 35 ayat (3) Undang-Undang Republik Indonesia Nomor 12 tahun 2012 tentang Pendidikan Tinggi, yang dimaksud dengan mata Kuliah Pendidikan Pancasila adalah pendidikan untuk memberikan pemahaman dan penghayatan kepada mahasiswa mengenai ideologi bangsa indonesia. Dengan landasan tersebut, Direktorat Jenderal Pendidikan Tinggi mengembangkan esensi materi Pendidikan Pancasila yang meliputi: 1. Pengantar Perkuliahan Pendidikan Pancasila 2. Pancasila dalam Kajian Sejarah Bangsa Indonesia 3. Pancasila sebagai Dasar Negara 4. Pancasila sebagai Ideologi Negara 5. Pancasila sebagai Sistem Filsafat 6. Pancasila sebagai Sistem Etika 7. Pendekatan Pembelajaran Dasar Nilai Pengembangan Ilmu. 
Pendekatan Pembelajaran yang direkomendasikan dalam Mata Kuliah Pendidikan Pancasila adalah pendekatan pembelajaran yang berpusat kepada mahasiswa (student ctered learning). Untuk memahami dan menghayati nilai-nilai Pancasila baik sebagai etika, filsafat negara, maupun ideologi bangsa secara scientific.

Dengan harapan nilai-nilai Pancasila akan terinternalisasi sehingga menjadi guiding principles atau kaidah penuntun bagi mahasiswa dalam mengembangkan jiwa profesionalismenya sesai dengan jurusan/program studi masing-masing. Implikasi dari Pendidikan Pancasila tersebut agar mahasiswa dapat menjadi insan profesional yang berjiwa pancasila dalam kehidupan bermasyarakat dan bernegara. Selain itu, urgensi Pendidikan Pancasila adalah untuk membentengi dan menjawab tantangan perubahan-perubahan di masa akan datang. Sebagai warga negara yang di bentuk dari sistem Pendidikan Ondonesia saat ini perlu mengetahui cita-cita yang harus dicapai dimasa yang akan datang sehingga dapat sebagai pijakan agar kehidupannya menjadi damai dan sejahtera.

Dalam Undang-Undang Republik Indonesia Nomor 20 Tahun 2003, Pasal 3 menegaskan bahwa Pendidikan Nasional berfungsi mengembangkan dan membentuk watak serta perdaban bangsa yang bermatabat dalam rangka mencerdaskan kehidupan bangsa, bertujuan untuk berkembangnya potensi peserta didik agar menjadi manusia yang beriman dan bertakwa kepada tuhan yang maha esa, berakhlak mulia, sehat, berilmu, cakap, kreatif, mandiri, dan menjadi warga negara yang demokratis serta tanggung jawab. Harapan tersebut memang tidak mudah untuk diwujudkan. Akan tetapi, pendidikan adalah alternatif baik dalam melakukan rekayasa sosial secara damai. Pendidikan adalah alternatif terbaik dalam melakukan sosial secara damai. Pendidikan Pancasila di perrguruan tinggi, perkenannya dengan memberikan kontribusi dalam pendalaman penghayatan dan penerapan nilai-nilai Pancasila kepada generasi baru banga. Atas 
dasar hal tersebut ,maka pemerintah menggunakan atau mengalokasikan $20 \%$ dan APBN yang sebagian bersal dari pajak untuk membiayai pendidikan nasional Setiap warga negara sesuai dengan kemampuan dan tingkatnya pendidikannya harus memiliki pengetahuan, pemahaman, penghayatan, penghargaan, komitmen, dan pengalaman Pancasila, lebih-lebih para mahasiwa yang notabene merupakan calon-calon pemegang tongkat estafet kepemimpinan bangsa harus memiliki penghayatan terhadap nilai-nilai pancasila karena akan menentukan eksistensi bangsa kedepan.

Urgensi Pendidikan Pancasila di peguruan tinggi ini berlaku untuk semua jurusan/program studi, sebab nasib bangsa tidak hanya di tentukan oleh segelintir profesi yang di hasilkan oleh sekelompok jurusan/program studi saja, tetapi juga merupakan tanggung jawab semua bidang. Urgensi Pendidikan Pancasila bagi suatu program studi, misalnya yang berkaitan dengan tugas menyusun/membentuk peraturan perundang-undangan. Orang yang bertugas untuk melaksanakan hal tersebut, harus mempunyai pengetahuan, pengertian, pemahaman, penghargaan, komitmen, penghayatan dan pola pengalaman yang lebih baik daripada warga negara yang lain karena merekalah yang akan menentukan merasap atau tidaknya 4 nilai-nilai pancasila ke dalam peraturan perundang-undangan yang di susun/dibentuknya. Lulusan/output dari program studi energi di kemudian hari akan menentukan kebijakan tentang eksplorasi, eksploitasi, industrialisasi, dan distribusi energi dijalankan.

Begitu pula dengan lulusan/output dari program studi perpajakan yang akan menjadi pengawai pajak maupun bekerja di bidang perpajakan dituntut memiliki kejujuran dan komitmen sehingga dapat memberikan kontribusi terhadap pelaksanaan kewajiban perpajakan tempat bekerja secara baik dan benar. Demikian pula halnya bahwa keberadaan pendidikan pancasila merupakan suatu yang esensial bagi program studi di perguruan tinggi. Oleh karena itu, menjadi 
suatu kewajaran bahkan keharusan Pancasila di sebarluaskan secara masif, antara lain melalui mata kuliah pendidikan pancasila di perguruan tinggi. Dalam hal ini, Riyanto (2009: 4) menyatakan bahwa pendidikan pancasila di perguruan tinggi merupakan suatu keniscayaan karena mahasiswa sebagai agen perubahan dan intelektual muda yang di masa akan datang akan menjadi inti pembangunan dan pemegang estafet kepemimpinan bangsa dalam setiap tingkatan lembaga-lembaga negara, badan-badan negara, lembaga daerah, lembaga intfrastruktur politik, lembaga-lembaga bisnis, dan sebagainya.

Dengan demikian, pemahaman nilai-nilai pancasila di kalangan mahasiswa amat penting, tanpa membedakan pilihan profensinya di masa yang akan datang, baik yang berprofensi sebagai

pengusaha/entrepreneur, pengawai swasta, pegawai pemerintah, dan sebagainya. Semua lapisan masyarakat memiliki peran amat menentukan terhadap eksistensi dan kejayaan bangsa di masa depan.

\section{B. PEMBAHASAN}

Sosiologi dipahami sebagai ilmu tentang kehidupan antarmanusia. Di dalamnya mengkaji, antara lain latar belakang, susunan dan pola kehidupan sosial dari berbagai golongan dan kelompok masyarakat, disamping juga mengkaji masalah-masalah sosial, perubahan dan pembaharuan dalam masyarakat. Dalam perspektif sosiologi, suatu masyarakat pada suatu waktu dan tempat memiliki nilai-nilai yang tertentu. Melalui pendekatan sosiologis ini pula, Anda diharapkan dapat mengkaji struktur sosial, proses sosial, termasuk perubahan-perubahan sosial, dan masalah-masalah sosial yang patut disikapi secara arif dengan menggunakan standar nilainilai yang mengacu kepada nilai-nilai Pancasila. 
Berbeda dengan bangsa-bangsa lain, bangsa Indonesia mendasarkan pandangan hidupnya dalam bermasyarakat, berbangsa, dan bernegara pada suatu asas kultural yang dimiliki dan melekat pada bangsa itu sendiri. Nilainilai kenegaraan dan kemasyarakatan yang terkandung dalam sila-sila Pancasila bukan hanya hasil konseptual seseorang saja, melainkan juga hasil karya besar bangsa Indonesia sendiri, yang diangkat dari nilai-nilai kultural yang dimiliki oleh bangsa Indonesia sendiri melalui proses refleksi filosofis para pendiri negara.

Bung Karno menegaskan bahwa nilai-nilai Pancasila digali dari bumi pertiwi Indonesia. Dengan kata lain, nilai-nilai Pancasila berasal dari kehidupan sosiologis masyarakat Indonesia. Pernyataan ini tidak diragukan lagi karena dikemukakan oleh Bung Karno sebagai penggali Pancasila, meskipun beliau dengan rendah hati membantah apabila disebut sebagai pencipta Pancasila, sebagaimana dikemukakan Beliau dalam paparan sebagai berikut: Kenapa diucapkan terima kasih kepada saya, kenapa saya diagung-agungkan, padahal toh sudah sering saya katakan, bahwa saya bukan pencipta Pancasila.

Saya sekedar penggali Pancasila daripada bumi tanah air Indonesia ini, yang kemudian lima mutiara yang saya gali itu, saya persembahkan kembali kepada bangsa Indonesia. Malah pernah saya katakan, bahwa sebenarnya hasil, atau lebih tegas penggalian daripada Pancasila ini saudara-saudara, adalah pemberian Tuhan kepada sayzza, Sebagaimana tiap-tiap manusia, jikalau ia benar-benar memohon kepada Allah Subhanahu Wata' ala, diberi ilham oleh Allah Subhanahu Wata' ala. Makna penting lainnya dari pernyataan Bung Karno tersebut adalah Pancasila sebagai dasar negara merupakan pemberian atau ilham dari Tuhan Yang Maha Kuasa. Apabila dikaitkan dengan teori kausalitas dari Notonegoro bahwa Pancasila merupakan penyebab lahirnya (kemerdekaan) bangsa Indonesia, maka kemerdekaan berasal dari Allah, Tuhan Yang Maha Esa. Hal ini sejalan dengan makna Alinea III Pembukaan UUD 1945. Sebagai 
makhluk Tuhan, sebaiknya segala pemberian Tuhan, termasuk kemerdekaan Bangsa Indonesia ini wajib untuk disyukuri.

Salah satu bentuk wujud konkret mensyukuri nikmat karunia kemerdekaan adalah dengan memberikan kontribusi pemikiran terhadap pembaharuan dalam masyarakat. Bentuk lain mensyukuri kemerdekaan adalah dengan memberikan kontribusi konkret bagi pembangunan negara melalui kewajiban membayar pajak, karena dengan dana pajak itulah pembangunan dapat dilangsungkan secara optimal. Sejalan dengan hal itu, Anda juga diharapkan dapat berpartisipasi dalam meningkatkan fungsi-fungsi lembaga pengendalian sosial (agent of social control) yang mengacu kepada nilai-nilai Pancasila. Dalam rangka mensyukuri karunia kemerdekaan, Anda diminta untuk mengidentifikasi sekurang-kurangnya fenomena permasalahan sosial yang menurut Anda tidak sesuai dengan nilai-nilai Pancasila. Kemudian, Anda diminta untuk membuat ringkasan secara tertulis untuk diserahkan kepada dosen.

Sumber Yuridis Pendidikan Pancasila Negara Republik Indonesia adalah negara hukum (rechtsstaat) dan salah satu cirinya atau istilah yang bernuansa bersinonim, yaitu pemerintahan berdasarkan hukum (rule of law). Pancasila sebagai dasar negara merupakan landasan dan sumber dalam membentuk dan menyelenggarakan negara bangsa lemah dan penguasaan IPTEKS lemah, maka bangsa Indonesia dapat kembali terjajah atau setidak-tidaknya daya saing bangsa melemah. Implikasi dari pendekatan historis ini adalah meningkatkan motivasi kejuangan bangsa dan meningkatkan motivasi belajar Anda dalam menguasai IPTEKS sesuai dengan prodi masingmasing. Berdasarkan penjelasan di atas, Anda dipersilakan mencari fakta-fakta historis dan pelajaran yang menginspirasi Anda dari berbagai sumber, guna memberikan kontribusi yang konstruktif bagi masa depan bangsa yang lebih baik. Kemudian, Anda diminta untuk melaporkan secara tertulis kepada dosen. 
Sumber Sosiologis Pendidikan Pancasila Sosiologi dipahami sebagai ilmu tentang kehidupan antarmanusia. Di dalamnya mengkaji, antara lain latar belakang, susunan dan pola kehidupan sosial dari berbagai golongan dan kelompok masyarakat, disamping juga mengkaji masalah-masalah sosial, perubahan dan pembaharuan dalam masyarakat. Soekanto (1982:19) menegaskan bahwa dalam perspektif sosiologi, suatu masyarakat pada suatu waktu dan tempat memiliki nilai-nilai yang tertentu. Melalui pendekatan sosiologis ini pula, Anda diharapkan dapat mengkaji struktur sosial, proses sosial, termasuk perubahan-perubahan sosial, dan masalahmasalah sosial yang patut disikapi secara arif dengan menggunakan standar nilai-nilai yang mengacu kepada nilai-nilai Pancasila. Berbeda dengan bangsa-bangsa lain, bangsa Indonesia mendasarkan pandangan hidupnya dalam bermasyarakat, berbangsa, dan bernegara pada suatu asas kultural yang dimiliki dan melekat pada bangsa itu sendiri. Nilainilai kenegaraan dan kemasyarakatan yang terkandung dalam sila-sila Pancasila bukan hanya hasil konseptual seseorang saja, melainkan juga hasil karya besar bangsa Indonesia sendiri, yang diangkat dari nilai-nilai kultural yang dimiliki oleh bangsa Indonesia sendiri melalui proses refleksi filosofis para pendiri negara.

Bung Karno menegaskan bahwa nilai-nilai Pancasila digali dari bumi pertiwi Indonesia. Dengan kata lain, nilai-nilai Pancasila berasal dari kehidupan sosiologis masyarakat Indonesia. Pernyataan ini tidak diragukan lagi karena dikemukakan oleh Bung Karno sebagai penggali Pancasila, meskipun beliau dengan rendah hati membantah apabila disebut sebagai pencipta Pancasila, sebagaimana dikemukakan Beliau dalam paparan sebagai berikut: 30 " Kenapa diucapkan terima kasih kepada saya, kenapa saya diagung-agungkan, padahal toh sudah sering saya katakan, bahwa saya bukan pencipta Pancasila. Saya sekedar penggali Pancasila daripada bumi tanah air Indonesia ini, yang kemudian lima mutiara yang saya gali itu, saya persembahkan 
kembali kepada bangsa Indonesia. Malah pernah saya katakan, bahwa sebenarnya hasil, atau lebih tegas penggalian daripada Pancasila ini saudara-saudara, adalah pemberian Tuhan kepada saya.

Sebagaimana tiap-tiap manusia, jikalau ia benar-benar memohon kepada Allah Subhanahu Wata' ala, diberi ilham oleh Allah Subhanahu Wata' ala (Latif, 2011: 21) Makna penting lainnya dari pernyataan Bung Karno tersebut adalah Pancasila sebagai dasar negara merupakan pemberian atau ilham dari Tuhan Yang Maha Kuasa. Apabila dikaitkan dengan teori kausalitas dari Notonegoro bahwa Pancasila merupakan penyebab lahirnya (kemerdekaan) bangsa Indonesia, maka kemerdekaan berasal dari Allah, Tuhan Yang Maha Esa. Hal ini sejalan dengan makna Alinea III Pembukaan UUD 1945. Sebagai makhluk Tuhan, sebaiknya segala pemberian Tuhan, termasuk kemerdekaan Bangsa Indonesia ini wajib untuk disyukuri. Salah satu bentuk wujud konkret mensyukuri nikmat karunia kemerdekaan adalah dengan memberikan kontribusi pemikiran terhadap pembaharuan dalam masyarakat. Bentuk lain mensyukuri kemerdekaan adalah dengan memberikan kontribusi konkret bagi pembangunan negara melalui kewajiban membayar pajak, karena dengan dana pajak itulah pembangunan dapat dilangsungkan secara optimal. Sejalan dengan hal itu, Anda juga diharapkan dapat berpartisipasi dalam meningkatkan fungsi-fungsi lembaga pengendalian sosial (agent of social control) yang mengacu kepada nilai-nilai Pancasila

\section{PENUTUP}

Urgensi Pendidikan Pancasila dapat memperkokoh jiwa kebangsaan mahasiswa sehing ga menjadi dorongan pokok dan penunjuk jalan bagi calon pemegang estafet kepemimpinan bangsa di berbagai bidang dan tingkatan. Calon generasi kepemimpinan bangsa tidak mudah 
terpengaruh oleh paham-paham asing yang dapat mendorong untuk tidak dijalankannya nilainilai Pancasila. Pentingnya Pendidikan Pancasila diperguruan tinggi adalah untuk menjawab tantangan dunia dengan mempersiapkan warga negara yang menpunyai pengetahuan, pemahaman, penghargaan, penghayatan, komitmen dan pola pengamalan Pancasila. Untuk melahirkan lulusan yang menjadi kekuatan inti pembangunan, generasi muda bangsa dalam setiap tingkatan lembaga-lembaga negara, badan-badan negara, lembaga daerah, lembaga infrastruktur politik, dan lembaga lain menjunjung tinggi nilai-nilai luhur Pancasila.

\section{DAFTAR PUSTAKA}

Darmini Roza dan Laurensius Arliman S Peran Pemerintah Daerah Di Dalam Melindungi Hak Anak Di Indonesia, Masalah-Masalah Hukum, Volume 47, Nomor 1, 2018.

Laurensius Arliman S, Komnas HAM dan Perlindungan Anak Pelaku Tindak Pidana, Deepublish, Yogyakarta, 2015.

Laurensius Arliman S, Penguatan Perlindungan Anak Dari Tindakan Human Trafficking Di Daerah Perbatasan Indonesia, Jurnal Selat, Volume 4, Nomor 1, 2016.

Laurensius Arliman S, Problematika Dan Solusi Pemenuhan Perlindungan Hak Anak Sebagai Tersangka Tindak Pidana Di Satlantas Polresta Pariaman, Justicia Islamica, Volume 13, Nomor 2, 2016.

Laurensius Arliman S, Pelaksanaan Perlindungan Anak Yang Tereksploitasi Secara Ekonomi Oleh Pemerintah Kota Padang, Veritas et Justitia, Volume 2, Nomor 1, 2016.

Laurensius Arliman S, Kedudukan Ketetapan MPR Dalam Hierarki Peraturan PerundangUndangan Di Indonesia, Lex Jurnalica, Volume 13, Nomor 3, 2016.

Laurensius Arliman S, Komnas Perempuan Sebagai State Auxialiary Bodies Dalam Penegakan Ham Perempuan Indonesia, Justicia Islamica, Volume 14, Nomor 2, 2017.

Laurensius Arliman S, Peranan Pers Untuk Mewujudkan Perlindungan Anak Berkelanjutan Di Indonesia, Jurnal Ilmu Hukum Tambun Bungai, Volume 2, Nomor 2, 2017.

Laurensius Arliman S, Mewujudkan Penegakan Hukum Yang Baik Untuk Mewujudkan Indonesia Sebagai Negara Hukum, Jurnal Hukum Doctrinal, Volume 2, Nomor 2, 2017. 
Laurensius Arliman S, Participation Non-Governmental Organization In Protecting Child Rights In The Area Of Social Conflict, The 1st Ushuluddin and Islamic Thought International Conference (Usicon), Volume 1, 2017.

Laurensius Arliman S, Partisipasi Masyarakat Dalam Pembentukan Perundang-Undangan Untuk Mewujudkan Negara Kesejahteraan Indonesia, Jurnal Politik Pemerintahan Dharma Praja, Volume 10, Nomor 1, 2017, https://doi.org/10.33701/jppdp.v10i1.379.

Laurensius Arliman S, Peran Komisi Perlindungan Anak Indonesia Untuk Mewujudkan Perlindungan Anak, Jurnal Respublica Volume 17, Nomor 2, 2018.

Laurensius Arliman S, Menjerat Pelaku Penyuruh Pengrusakan Barang Milik Orang Lain Dengan Mempertimbangkan Asas Fungsi Sosial, Jurnal Gagasan Hukum, Volume 1, Nomor 1, 2019.

Laurensius Arliman S, Ilmu Perundang-Undangan Yang Baik Untuk Negara Indonesia, Deepublish, Yogyakarta, 2019.

Laurensius Arliman S, Isdal Veri, Gustiwarni, Elfitrayenti, Ade Sakurawati, Yasri, Pengaruh Karakteristik Individu, Perlindungan Hak Perempuan Terhadap Kualitas Pelayanan Komnas Perempuan Dengan Kompetensi Sumber Daya Manusia Sebagai Variabel Mediasi, Jurnal Menara Ekonomi: Penelitian dan Kajian Ilmiah Bidang Ekonomi, Volume 6, Nomor 2, 2020.

Laurensius Arliman S, Pendidikan Kewarganegaraan, Deepublish, Yogyakarta, 2020.

Laurensius Arliman S, Makna Keuangan Negara Dalam Pasal Pasal 23 E Undang-Undang Dasar 1945, Jurnal Lex Librum, Volume 6, Nomor 2 Juni 2020, http://dx.doi.org/10.46839/1ljih.v6i2.151.

Laurensius Arliman S, Kedudukan Lembaga Negara Independen Di Indonesia Untuk Mencapai Tujuan Negara Hukum, Kertha Semaya Journal Ilmu Hukum, Volume 8, Nomor 7, 2020.

Laurensius Arliman S, Pelaksanaan Assesment Oleh Polres Kepulauan Mentawai Sebagai Bentuk Pelaksanaan Rehabilitasi Bagi Pecandu Dan Korban Penyalahgunaan Narkotika, Jurnal Muhakkamah, Volume 5, Nomor 1, 2020.

Laurensius Arliman S, Aswandi Aswandi, Firgi Nurdiansyah, Laxmy Defilah, Nova Sari Yudistia, Ni Putu Eka, Viona Putri, Zakia Zakia, Ernita Arief, Prinsip, Mekanisme Dan Bentuk Pelayanan Informasi Kepada Publik Oleh Direktorat Jenderal Pajak, Volume 17, No Nomor, 2020.

Larensius Arliman S, Koordinasi PT. Pegadaian (Persero) Dengan Direktorat Reserse Narkoba Polda Sumbar Dalam Penimbangan Barang Bukti Penyalahgunaan Narkotika, UIR Law Review, Volume 4, Nomor 2, 2020, https://doi.org/10.25299/uirlrev.2020.vol4(1).3779. 
Laurensius Arliman S, Tantangan Pendidikan Kewarganegaraan Pada Revolusi 4.0, Ensiklopedia Sosial Review, Volume 2, Nomor 3, 2020.

Muhammad Afif dan Laurensius Arliman S, Protection Of Children's Rights Of The Islamic And Constitutional Law Perspective Of The Republic Of Indonesia, Proceeding: Internasional Conference On Humanity, Law And Sharia (Ichlash), Volume 1, Nomor 2, 2020.

Otong Rosadi danLaurensius Arliman S, Urgensi Pengaturan Badan Pembinaan Idelogi Pancasila Berdasarkan Undang-Undang Sebagai State Auxiliary Bodies yang Merawat Pancasila dalam Perspektif Hak Asasi Manusia, Prosiding Konferensi Nasional Hak Asasi Manusia, Kebudayaan dan Tujuan Pembangunan Berkelanjutan Indonesia pada Masa Pandemi Covid-19: Tantangan untuk Keilmuan Hukum dan Sosial Volume 1, Universitas Pancasila, Jakarta, 2020. 